\title{
Assessing the role of habitat and species interactions in the population decline and detection bias of Neotropical leaf litter frogs in and around La Selva Biological Station, Costa Rica
}

\author{
Avaliação do papel das interações entre espécies \\ e habitats no declínio populacional e no viés de \\ detecção de rãs neotropicais da serapilheira na \\ Estação Biológica La Selva e arredores, Costa Rica
}

\author{
Maria D. Vera Alvarez', Christopher Fernandez², Michael V. Cove ${ }^{3}$ \\ 1 Virginia Commonwealth University, Richmond, VA 23220, USA \\ 2 George Mason University, Fairfax, VA 22030, USA \\ 3 Department of Applied Ecology, North Carolina State University, Raleigh, NC 27695, USA \\ Corresponding author: Michael V. Cove (mvcove@ncsu.edu)
}

Academic editor:A.M. Leal-Zanchet | Received 28 December 2018 | Accepted 26 April 2019 | Published 15 July 2019

Citation: Vera Alvarez MD, Fernandez C, Cove MV (2019) Assessing the role of habitat and species interactions in the population decline and detection bias of Neotropical leaf litter frogs in and around La Selva Biological Station, Costa Rica. Neotropical Biology and Conservation 14(2): 143-156. https://doi.org/10.3897/neotropical.14.e37526

\begin{abstract}
Worldwide, amphibian populations have been declining rapidly. This decline can be attributed to many factors including climate change, pesticide exposure, and emerging infectious diseases, among other important factors, but few studies have examined the influence of species interactions. In this study, we examined how habitat factors and co-occurring avian and mammalian species, as well as humans, exert direct and indirect effects on Neotropical amphibian population dynamics. We further examined how these habitat and species interactions could affect our ability to reliably detect
\end{abstract}


amphibian presence to robustly estimate population trends. We conducted amphibian visual encounter surveys at 26 randomly selected sites in the La Selva Biological Station, in northeastern Costa Rica, as well as 26 sites across five additional forest fragments in the region. Furthermore, we used camera traps to collect data on avian and mammalian communities and human visitation at those amphibian survey plots. From these data, we were able to estimate species occupancy probabilities for leaf litter frogs across sites and their relationships to habitat and interspecific species interaction covariates. We also conducted an experiment with plastic model frogs to estimate detection probabilities when a population is known to occur at a site with certainty. Our results suggested that strawberry poison dart frog (Oophaga pumilio) occupancy was positively related to secondary forest and their detection was negatively related to increasing air temperatures at the times of the surveys. Leaf litter frog occupancy was negatively related to core La Selva sites and human detections at sites, yet their detection was positively related to human trail presence, which might be related to reduced leaf litter cover due to heavy trampling. Our experimental surveys suggested that Neotropical leaf litter frog communities are difficult to detect when present and future studies should explicitly account for this detection bias to effectively monitor population trends.

\section{Resumo}

Em todo o mundo, as populações de anfíbios têm diminuído rapidamente. Esse declínio pode ser atribuído a muitos fatores, incluindo mudanças climáticas, exposição a pesticidas e doenças infecciosas emergentes, mas poucos estudos examinaram a influência das interações entre espécies. Neste estudo, examinamos como os fatores de habitat e as espécies de aves e de mamíferos que coexistem, bem como os humanos, exercem efeitos diretos e indiretos sobre a dinâmica populacional de anfíbios neotropicais. Além disso, examinamos como essas interações de habitat e espécies poderiam afetar nossa capacidade de detectar com segurança a presença de anfíbios para estimar tendências populacionais de maneira robusta. Realizamos pesquisas de encontros visuais com anfíbios em 26 locais selecionados aleatoriamente na Estação Biológica La Selva, no nordeste da Costa Rica, além 26 sítios de cinco fragmentos florestais adicionais na região. Além disso, usamos armadilhas fotográficas para coletar dados sobre comunidades de aves e mamíferos e visitação humana nessas parcelas de pesquisa de anfíbios. A partir desses dados, pudemos estimar as probabilidades de ocupação de espécies para dois grupos de rãs de serapilheira em locais dependentes de habitat e covariáveis de interação interespecífica. Também realizamos um experimento com modelos de plástico para estimar as probabilidades de detecção quando se sabe com certeza que uma população ocorre em um local. Nossos resultados sugerem que a ocupação pela rã morango (Oophaga pumilio) esteve positivamente relacionada à floresta secundária e sua deteç̧ão, negativamente relacionada com o aumento da temperatura do ar nos períodos dos levantamentos. A ocupação por rãs de serapilheira esteve negativamente relacionada com os sítios centrais de La Selva e detecções humanas nos sítios, ainda que sua detecção tenha estado positivamente relacionada à presença de trilhas humanas, o que pode ser explicado pela redução da cobertura da serapilheira devido ao pisoteio intenso. Os resultados sugerem que as comunidades de rãs neotropicais da serapilheira são difíceis de detectar em campo; estudos futuros devem considerar esse viés de detecção para monitorar efetivamente as tendências populacionais.

\section{Keywords}

Anurans, community ecology, detection probability, leaf litter frogs, occupancy models

\section{Palavras-chave}

Anuros, ecologia de comunidades, modelos de ocupação, probabilidade de detecção, rãs de serapilheira 


\section{Introduction}

Amphibian populations worldwide have declined rapidly over the last few decades (Carey 2000). There are many hypotheses that attempt to explain this phenomenon, but the major factors implicated in their decline are human-induced habitat loss, invasive species and disease outbreaks (Whitfield et al. 2007; Cove and Spinola 2014). Lips et al. (2003) suggested that frogs, in particular, are highly affected by climate change, environmental stress and habitat change, suggesting, in addition, that frogs are useful environmental indicators (Phillips, 1990). Amphibian declines can occur anywhere, even in mostly intact and protected forest, for example, the well-protected La Selva Biological Station in northeastern Costa Rica has been experiencing rampant and enigmatic declines of this group of animals in recent history (Whitfield et al. 2007).

Whitfield et al. (2014) observed that leaf litter provides valuable habitat and prey resources making it vital to many amphibian populations in the tropics. Leaf litter is affected by climate dynamics, but also by mammalian taxa that trample, root, and dig through it (Reider et al. 2013). For example, collared peccaries (Pecari tajacu Linnaeus, 1758) have experienced recent population growth at La Selva (Romero et al. 2013), which one would think exerts an impact on amphibian communities, but different research studies have revealed varied results. Reider et al. (2013) suggested that herpetofauna are positively related to collared peccary occurrence via the comparison of frog counts from peccary exclosure plots to control plots. Yet, McKone et al. (2014) hypothesized that collared peccaries are responsible for bromeliad declines and are therefore indirectly causing declines in strawberry poison dart frog (Oophaga pumilio Schmidt, 1857) populations. However, neither study has measured or directly incorporated peccary (or other predator) abundance data into their analyses. Additionally, many other potential avian and mammalian predators of frogs commonly occur in and around La Selva (e.g., great curassow [Crax rubra Linnaeus, 1758] and white-nosed coati [Nasua narica Linnaeus, 1766] - Paluh et al. 2015; Pardo et al. 2016; Pardo et al. 2017), which could also have an effect on amphibian communities due to predation or trampling and rooting of leaf litter habitat at various scales. Furthermore, humans and their use of trails may further influence frog communities due to additional trampling of leaf litter affecting the microclimate and cover from predators.

To examine these potential interspecific species interactions and habitat associations, we conducted an observational study paired with a follow-up experiment to assess the reliability of our observations. Previous studies failed to account for possible detection bias due to cryptic coloring of many leaf litter frogs or habitatspecific detection probabilities, which have been suggested to strongly influence inferences in herpetological studies (Mazerolle et al. 2007). The advent of occupancy models has strengthened our ability to make strong inferences, particularly about amphibian population trends by incorporating detection probability as a nuisance 
parameter in repeated population surveys (MacKenzie et al. 2006). During the observational study, we used repeated independent surveys of leaf litter frog populations at forested sites along a gradient of fragmentation and succession and used camera traps to evaluate potential avian and mammalian direct and indirect effects into frogs' occurrence models. Then, we estimated the probability of detecting frogs when present in an experimental survey of a known population of plastic frog models across the same study sites. We predicted that avian and mammalian predators and other medium to large mammals and humans, due to their trampling and changes to leaf litter dynamics, as well as fragmentation effects would all play a role in affecting the distribution and detection of frogs across our survey plots.

\section{Methods}

\section{Observational surveys}

We conducted this research on the 1600 ha La Selva Biological Station in northeastern Costa Rica. La Selva annually receives $\sim 4 \mathrm{~m}$ of rain, with a dry season from January to April, and average temperature approximately of $25{ }^{\circ} \mathrm{C}$. Elevation on this reserve ranges from 30 to $135 \mathrm{~m}$ (Michel et al. 2014). We conducted amphibian visual encounter surveys (sensu Reider et al. 2013). The survey plots were $10 \mathrm{~m} \mathrm{x}$ $10 \mathrm{~m}$, which were half the size of study plots from previous research (e.g., Reider et al. 2013). At the center of each plot, we established camera traps (Reconyx PC800 or PC850, RECONYX, Inc., Holmen WI, USA) to take 10 rapid-fire photos whenever motion was detected, but also set them to capture shots every hour in order to detect other potential amphibian predators such as snakes. The plots were smaller than previous research so that camera traps could more appropriately detect avian and mammalian species that entered the survey plots. We deployed cameras for a period of 6-7 trapnights. Surveys occurred within core La Selva $(n=26)$ and at five additional forest fragments $(n=26)$ in the region to assess landscape-scale habitat effects of core versus fragmented habitat (Figure 1). Furthermore, we randomly selected plots for surveys as either on human trails $(n=24)$ or away from human trails $(>20 \mathrm{~m}-\mathrm{n}=28)$ to examine local-scale edge effects since the human trails are wide and cleared, we considered these to create forest edges and affect leaf litter dynamics due to trampling by humans and other mammals. Sites corresponded with concurrent surveys of ground-nest predators (Cove et al. 2017; Fernandez and Cove 2016).

We conducted the leaf litter frog surveys from 2 to 4 days after the plot was established with the camera trap. During each survey, two independent observers walked a slow zig-zagging pace through the entire plot from opposite ends, making sure to not resample or double-count the amphibians encountered. We did not capture or manipulate any animals, but we did use a $2 \mathrm{~m}$ long PVC pipe to gently rustle leaves so that frogs could avoid being stepped on by observers. Because we did not capture any individuals, we categorized frogs into two observable classes (Figure 2a, b). Dendrobatids, particularly Oophaga pumilio, were aposematic and distinguishable from other species, so these were counted separately from other species. They presumably 


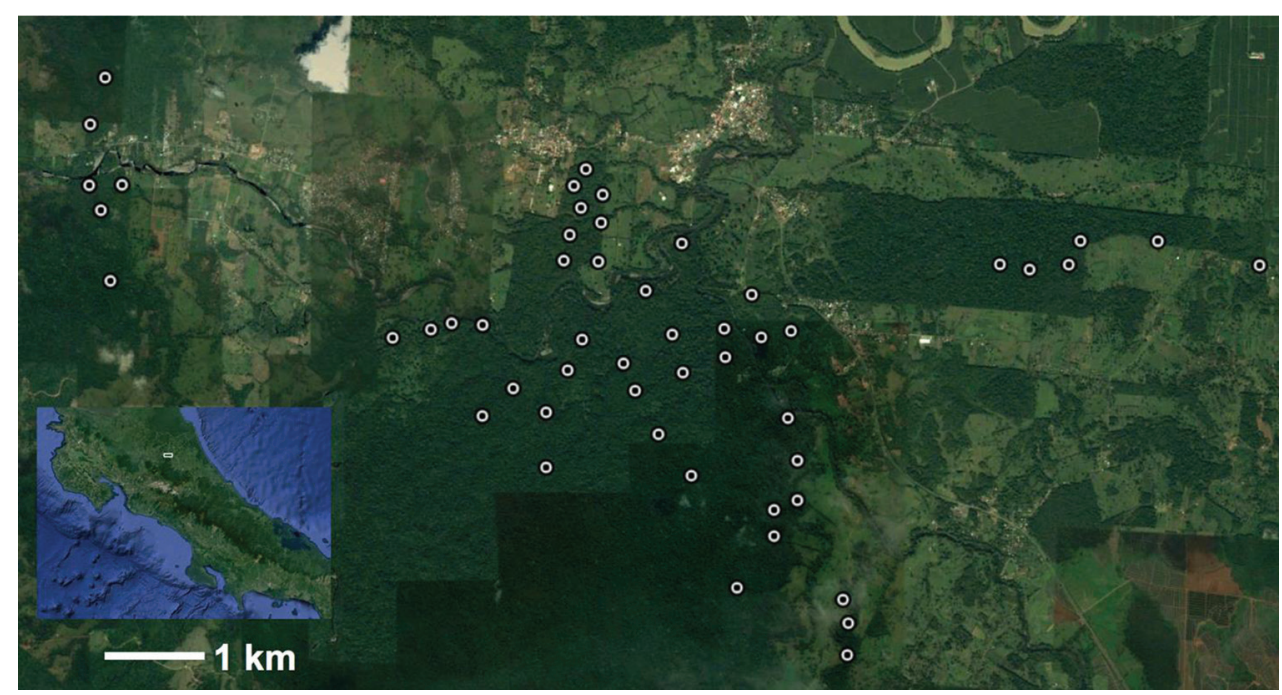

Figure 1. Site locations of 52 observational and experimental surveys of leaf litter frogs from La Selva Biological Station core forest and forest fragment sites in the San Juan-La Selva Biological Corridor, Costa Rica (inset), June-July 2016.

are less likely to suffer from direct predation due to their toxic skin secretions and hence might show a different response from other leaf litter frogs (Paluh et al. 2015). We considered all other frogs that were cryptic among leaf litter (e.g., Bufonidae, Craugastoridae, etc.) to belong to the group "leaf litter frogs". Although leaf litter frogs presumably fill different niches and can be quite diverse, previous observations of encounter rates made us suspect that they are affected by the same potential effects of habitat disturbances and interspecific interactions with potential predators and have experienced declines in La Selva (Reider et al. 2013; Whitfield et al. 2007).

Logistical and weather constraints prevented multiple observers at some sites, but our modeling framework accounted for this uneven sampling (see Analyses). Each survey plot was walked within a 20 min window, but we recorded if the period was shortened as a potential covariate in later analyses, particularly because sites varied in their ease of survey. Each surveyor's transect was considered independent, so the total effort was $\sim 40$ human-minutes per plot, which was comparable to previous studies (Reider et al. 2013), but we also used these repeated surveys to explicitly account for and estimate detection bias (e.g., MacKenzie et al. 2006).

\section{Experimental surveys}

Immediately following the initial observational amphibian surveys conducted at each site, we established an experimental survey. One of the surveyors selected a random sample of plastic frog models to place in the environment for the other surveyor(s). The frog models ranged in size from $22-50 \mathrm{~mm}$ and were painted to represent four of the most commonly detected frogs (Oophaga pumilio, Craugastor bransfordii Cope, 1885, C. megacephalus Cope, 1875 , and Pristimantis cerasinus Cope, 1875) at La Sel- 


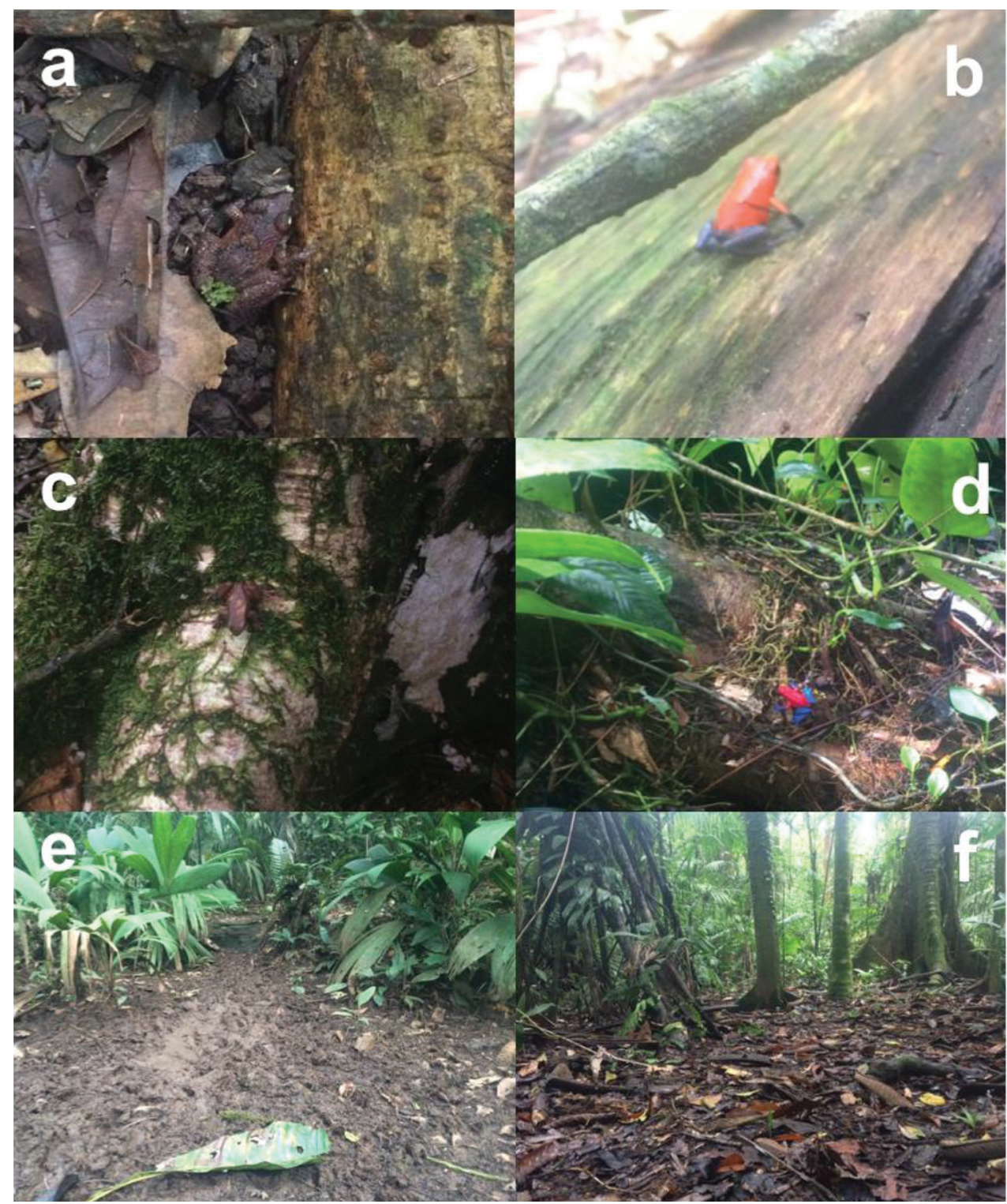

Figure 2. Sample photos of (a) leaf litter frog and (b) strawberry poison dart frog (Oophaga pumilio), and examples of (c) leaf litter frog plastic frog model and (d) strawberry poison dart frog plastic frog model in the field, and site photos showing the difference in leaf litter between survey locations on trails (e) versus off trails (f) in La Selva Biological Station, Costa Rica.

va (e.g., Reider et al. 2013 - Figure 2c, d). The surveyor placed the frogs randomly throughout the plot, recorded the number of each group (e.g., poison dart frogs versus leaf litter frogs) and timed the experiment to be the same length as the previous amphibian surveys. One or two observers repeated the previous observational survey, without knowledge of the number of plastic frog models at the site. 


\section{Analyses}

We employed analytical approaches to account for variation in the detection process of frogs at each site. We used occupancy models (MacKenzie et al. 2006) to estimate site occupancy probabilities ( $\psi-$ e.g., the probability that a site is occupied) of each frog group. We created detection histories ( $1=$ detected, $0=$ not detected) as input for single season occupancy models within the freely available software PRESENCE (Hines 2012). We included covariates on both detection probability (p) and site occupancy $(\psi)$. We first compared seven detection models that included (1) temperature at time of survey (continuous), (2) rain conditions (binary, rain $=1$ ), (3) survey duration (continuous time), (4) surveyor-specific (categorical), (5) human trail (binary, trail =1), or (6) trample (as described later in text) covariates on detection probabilities (p) compared to a (7) constant detection model (e.g., no factors influence detection). From this model comparison, we included the top supported detection covariate in all further occupancy models (MacKenzie et al. 2006). In the subsequent occupancy models, we compared the descriptive value of seven site-specific covariates. These included a (8) binary covariate for sites directly on or off human trails (local edge effect - Figure 2e, f) and a (9) continuous covariate for distance to forest edge (landscape edge effect). Furthermore, we included a (10) core forest versus fragment binary covariate to distinguish between core forest in La Selva and forest fragments at the other five sites and a (11) binary covariate to distinguish forest age (e.g., primary versus secondary forest). We used camera trap data as covariates in occupancy models with a (12) total predator model that included the number of

Table 1. Model selection statistics for models predicting Oophaga pumilio occupancy $(\psi)$ and detection (p) from La Selva Biological Station core forest sites and forest fragment sites of the San Juan-La Selva Biological Corridor, Costa Rica, June-July 2016. Information presented for each model includes: The AICc values, AICc difference relative to the top model ( $\triangle \mathrm{AICc})$, Akaike weight of evidence in favor of a given model $\left(w_{i}\right)$, number of parameters $(\mathrm{k})$, and model likelihood (-2Log-likelihood). Bolded models exhibit the most useful explanatory value.

\begin{tabular}{lccccc}
\hline \multicolumn{1}{c}{ Model } & AICc & $\Delta$ AICc & $\boldsymbol{w}_{i}$ & k & -2Log-likelihood \\
\hline$\psi($ forest age), p(temperature) & $\mathbf{1 2 8 . 7 5}$ & $\mathbf{0 . 0 0}$ & $\mathbf{0 . 1 4 7}$ & $\mathbf{4}$ & $\mathbf{1 1 9 . 9 0}$ \\
$\psi(),. \mathbf{p}$ (temperature) & $\mathbf{1 2 8 . 9 8}$ & $\mathbf{0 . 2 3}$ & $\mathbf{0 . 1 3 1}$ & $\mathbf{3}$ & $\mathbf{1 2 2 . 4 8}$ \\
$\psi(),. \mathrm{p}()$. & 129.22 & 0.47 & 0.116 & 2 & 124.98 \\
$\psi(),. \mathrm{p}$ (observer) & 129.73 & 0.98 & 0.090 & 3 & 123.23 \\
$\psi($ core forest), p(temperature) & 129.89 & 1.14 & 0.083 & 4 & 121.04 \\
$\psi($ (predators), p(temperature) & 129.92 & 1.17 & 0.082 & 4 & 121.07 \\
$\psi($ (human trail), p(temperature) & 130.78 & 2.03 & 0.053 & 4 & 121.93 \\
$\psi($ distance to edge), p(temperature) & 131.06 & 2.31 & 0.046 & 4 & 122.21 \\
$\psi(),. \mathrm{p}$ (rain) & 131.09 & 2.34 & 0.046 & 3 & 124.59 \\
$\psi(),. \mathrm{p}$ (human trail) & 131.14 & 2.39 & 0.044 & 3 & 124.64 \\
$\psi($ (humans), p(temperature) & 131.21 & 2.46 & 0.043 & 4 & 122.36 \\
$\psi(),. \mathrm{p}$ (trample) & 131.32 & 2.57 & 0.041 & 3 & 124.82 \\
$\psi($ trample), p(temperature) & 131.33 & 2.58 & 0.040 & 4 & 122.48 \\
$\psi(),. \mathrm{p}$ (survey time) & 131.40 & 2.65 & 0.039 & 3 & 124.90 \\
\hline
\end{tabular}


Table 2. Model selection statistics for models predicting leaf litter frog occupancy ( $\psi$ ) and detection (p) from La Selva Biological Station core forest sites and forest fragment sites of the San Juan-La Selva Biological Corridor, Costa Rica, June-July 2016. Information presented for each model includes: The AICc values, AICc difference relative to the top model ( $\triangle \mathrm{AICc}$ ), Akaike weight of evidence in favor of a given model (wi), number of parameters (k), and model likelihood (-2Log-likelihood). Bolded models exhibit the most useful explanatory value.

\begin{tabular}{lccccc}
\hline \multicolumn{1}{c}{ Model } & AICc & $\Delta$ AICc & $\boldsymbol{w}_{\boldsymbol{i}}$ & $\mathbf{k}$ & -2Log-likelihood \\
\hline$\psi($ core forest), p(human trail) & $\mathbf{1 2 8 . 4 2}$ & $\mathbf{0 . 0 0}$ & $\mathbf{0 . 3 4 9}$ & $\mathbf{4}$ & $\mathbf{1 1 9 . 5 7}$ \\
$\psi(),. \mathbf{p}$ (human trail) & $\mathbf{1 3 0 . 2 5}$ & $\mathbf{1 . 8 3}$ & $\mathbf{0 . 1 4 0}$ & $\mathbf{3}$ & $\mathbf{1 2 3 . 7 5}$ \\
$\psi($ (humans),p(human trail) & $\mathbf{1 3 0 . 8 3}$ & $\mathbf{2 . 4 1}$ & $\mathbf{0 . 1 0 5}$ & $\mathbf{4}$ & $\mathbf{1 2 1 . 9 8}$ \\
$\psi(),. \mathrm{p}()$. & 131.30 & 2.88 & 0.083 & 2 & 127.06 \\
$\psi(),. \mathrm{p}$ (rain) & 131.72 & 3.30 & 0.067 & 3 & 125.22 \\
$\psi($ trample), p(human trail) & 131.89 & 3.47 & 0.062 & 4 & 123.04 \\
$\psi($ forest age), p(human trail) & 132.47 & 4.05 & 0.046 & 4 & 123.62 \\
$\psi($ distance to edge), p(human trail) & 132.56 & 4.14 & 0.044 & 4 & 123.71 \\
$\psi(),. \mathrm{p}$ (trample) & 132.66 & 4.24 & 0.042 & 3 & 126.16 \\
$\psi(),. \mathrm{p}$ (observer) & 132.95 & 4.53 & 0.036 & 3 & 126.45 \\
$\psi(),. \mathrm{p}$ (survey time) & 133.54 & 5.12 & 0.027 & 3 & 127.04 \\
\hline
\end{tabular}

Table 3. Model selection statistics from experimental surveys predicting plastic model Oophaga pumilio occupancy $(\psi)$ and detection (p) from La Selva Biological Station core forest sites and forest fragment sites of the San Juan-La Selva Biological Corridor, Costa Rica, June-July 2016. Information presented for each model includes: The AICc values, AICc difference relative to the top model $(\triangle \mathrm{AICc})$, Akaike weight of evidence in favor of a given model $\left(w_{i}\right)$, number of parameters $(\mathrm{k})$, and model likelihood (-2Log-likelihood).

\begin{tabular}{lccccc}
\hline \multicolumn{1}{c}{ Model } & AICc & $\Delta$ AICc & $\boldsymbol{w}_{\boldsymbol{i}}$ & k & -2Log-likelihood \\
\hline$\psi(),. \mathrm{p}()$. & 81.27 & 0.00 & 0.152 & 2 & 77.03 \\
$\psi(),. \mathrm{p}($ observer $)$ & 81.43 & 0.16 & 0.140 & 3 & 74.93 \\
$\psi(),. \mathrm{p}$ (rain) & 81.75 & 0.48 & 0.120 & 3 & 75.25 \\
$\psi(),. \mathrm{p}$ (forest age) & 81.91 & 0.64 & 0.110 & 3 & 75.41 \\
$\psi(),. \mathrm{p}$ (trample) & 82.75 & 1.48 & 0.073 & 3 & 76.25 \\
$\psi(),. \mathrm{p}$ (temperature) & 83.34 & 2.07 & 0.054 & 3 & 76.84 \\
$\psi(),. \mathrm{p}($ survey time) & 83.39 & 2.12 & 0.053 & 3 & 76.89 \\
$\psi($ forest age), p(.) & 83.49 & 2.22 & 0.050 & 3 & 76.99 \\
$\psi(),. \mathrm{p}$ (human trail) & 83.49 & 2.22 & 0.050 & 3 & 76.99 \\
$\psi($ distance to edge), p(.) & 83.50 & 2.23 & 0.050 & 3 & 77.00 \\
$\psi($ core forest), p(.) & 83.51 & 2.24 & 0.050 & 3 & 77.01 \\
$\psi(),. \mathrm{p}$ (core forest) & 83.51 & 2.24 & 0.050 & 3 & 77.01 \\
$\psi(),. \mathrm{p}$ (distance to edge) & 83.53 & 2.26 & 0.049 & 3 & 77.03 \\
\hline
\end{tabular}

potential avian and mammalian predator detections at a site. We also formulated a (13) trample model which included the detections of large and/or gregarious mammals (collared peccaries, white-nosed coatis, and red brocket deer [Mazama americana Erxleben, 1777]) and humans that affect leaf litter dynamics via trampling and/ or displacement. Finally, we included a (14) human model (e.g., number of human detections) to examine how their effect alone compared to avian and mammalian community members. We compared these 14 a priori models via AICc (corrected for small sample size) model selection and excluded models that failed to converge 
Table 4. Model selection statistics from experimental surveys predicting plastic model leaf litter frog occupancy $(\psi)$ and detection (p) from La Selva Biological Station core forest sites and forest fragment sites of the San Juan-La Selva Biological Corridor, Costa Rica, June-July 2016. Information presented for each model includes: The AICc values, AICc difference relative to the top model ( $\triangle \mathrm{AICc}$ ), Akaike weight of evidence in favor of a given model $\left(w_{i}\right)$, number of parameters $(\mathrm{k})$, and model likelihood (-2Log-likelihood).

\begin{tabular}{lccccc}
\hline \multicolumn{1}{c}{ Model } & AICc & DAICc & $w_{i}$ & k & -2Log-likelihood \\
\hline$\psi(),. \mathrm{p}($ survey time) & 84.41 & 0.00 & 0.291 & 3 & 77.91 \\
$\psi($ forest age),p(survey time) & 84.78 & 0.37 & 0.242 & 4 & 75.93 \\
$\psi($ distance to edge),p(survey time) & 85.36 & 0.95 & 0.181 & 4 & 76.51 \\
$\psi($ core forest),p(survey time) & 85.74 & 1.33 & 0.150 & 4 & 76.89 \\
$\psi(),. \mathrm{p}$ (human trail) & 89.06 & 4.65 & 0.029 & 3 & 82.56 \\
$\psi(),. \mathrm{p}($ core forest) & 89.46 & 5.05 & 0.023 & 3 & 82.96 \\
$\psi(),. \mathrm{p}$ (trample) & 89.82 & 5.41 & 0.020 & 3 & 83.32 \\
$\psi(),. \mathrm{p}()$. & 90.04 & 5.63 & 0.017 & 2 & 85.80 \\
$\psi(),. \mathrm{p}($ distance to edge) & 90.34 & 5.93 & 0.015 & 3 & 83.84 \\
$\psi(),. \mathrm{p}($ forest age) & 90.63 & 6.22 & 0.013 & 3 & 84.13 \\
$\psi(),. \mathrm{p}$ (observer) & 91.79 & 7.38 & 0.007 & 3 & 85.29 \\
$\psi(),. \mathrm{p}$ (temperature) & 91.93 & 7.52 & 0.007 & 3 & 85.43 \\
$\psi(),. \mathrm{p}($ rain) & 92.26 & 7.85 & 0.006 & 3 & 85.76 \\
\hline
\end{tabular}

from further comparisons. We considered models and their covariates to have useful explanatory value if they had substantial relative model Akaike weights $\left(w_{i}\right)$ and they outcompeted the null model $[\psi(),. \mathrm{p}()$.$] with constant occupancy and detection.$

\section{Results}

We conducted 93 independent repeated amphibian surveys across 52 different sites in total, as well as 51 experimental surveys for a known number of plastic frog models at the same sites. We observed 129 frogs across all sites. Of the 129 frogs, 70 were Oophaga pumilio and 59 were leaf litter frogs. From camera trap data, we detected 484 potential avian and mammalian predators and humans across core La Selva sites, compared to 138 potential avian and mammalian predator and human detections from across the forest fragment sites.

We detected strawberry poison dart frogs at 29 of the 52 sites (naïve occupancy $=56 \%)$. Two of the strawberry poison dart frog occupancy models received substantial Akaike weight and were more supported than the constant model (Table 1). The top supported model suggested that strawberry poison dart frog occupancy was negatively associated with primary forest cover $(\beta=-1.81 \pm 1.34 \mathrm{SE})$ as compared to secondary forest and tree plantations, leading to derived poison dart frog occupancy probability estimates of $\psi=0.55 \pm 0.19$ SE in primary forest and $\psi=0.88 \pm$ $0.14 \mathrm{SE}$ in secondary forest. Additionally, increasing temperature at the time of the surveys was negatively associated with frog detection $(\beta=-0.41 \pm 0.28 \mathrm{SE})$, with a detection probability of $p=0.54 \pm 0.10$ SE when surveys were conducted at the mean temperature of $28.9^{\circ} \mathrm{C}$. 
We detected leaf litter frogs at 31 of the 52 sites (naïve occupancy $=60 \%$ ). Three of the leaf litter frog occupancy models received substantial Akaike weight and were more supported than the constant model (Table 2). Leaf litter frog occupancy was negatively associated with core La Selva forest $(\beta=-3.82 \pm 9.22 \mathrm{SE}$ ), but was highly variable, leading to derived leaf litter frog occupancy probability estimates of $\psi=0.64 \pm 0.14 \mathrm{SE}$ in La Selva core forest and $\psi=0.99 \pm 0.11 \mathrm{SE}$ in forest fragments. The leaf litter frogs also exhibited higher detection probabilities on human trails $(\beta=1.28+0.61 \mathrm{SE})$, with derived estimates of $p=0.70 \pm 0.13 \mathrm{SE}$ on human trails compared to $p=0.39 \pm 0.08 \mathrm{SE}$ at sites away from human trails. Finally, the model with human detections on cameras was also supported with a negative association of leaf litter frog occupancy ( $\beta=-0.55 \pm 0.45 \mathrm{SE}$ ) with increasing human detections at each site.

For the experimental surveys using the plastic frog models there was no correlation between covariates and our ability to detect the Oophaga pumilio (Table 3). The probability of detecting the Oophaga plastic models when present was $p=0.88 \pm 0.08$ SE. The estimated occupancy was $0.74 \pm 0.089 \mathrm{SE}$ ( $95 \% \mathrm{CI}=0.53-0.88$ ), whereas the known occupancy was 0.82 , so our estimator was within 1 SE of the true state. The experimental surveys using the plastic leaf litter frog models showed a negative relationship with survey time ( $\beta=-1.45 \pm 0.65 \mathrm{SE}$ ), which was contradictory to our a priori hypothesis (Table 4 ). The estimate of occupancy was $0.71 \pm 0.14 \mathrm{SE}$ (95\% CI $=0.38-0.91)$, whereas the known occupancy was 0.82 , so our estimator was within $1 \mathrm{SE}$ of the true state, though further than the Oophaga estimate. The probability of detecting leaf litter frogs when present was $p=0.70 \pm 0.16 \mathrm{SE}$ given the average survey length of 13 minutes per plot in the experimental surveys.

\section{Discussion}

We detected leaf litter frogs and poison dart frogs fairly commonly across most sites, with detections of each group occurring at greater than $50 \%$ of sites and detections of at least one frog from either group at $79 \%$ of sites $(n=41)$. While these detections are not exceptionally low, they are not necessarily encouraging because previous research has suggested that there are ongoing declines of all herpetofauna at La Selva (Whitfield et al. 2007). We did not calculate species-specific densities so our inferences differ from previous research because they are general to strawberry poison dart frog and all 'leaf litter frogs' occurrence as opposed to abundance, which would be more indicative of species-specific declines.

Our survey of Oophaga pumilio showed steady, but low numbers of strawberry poison dart frogs across our sites similar to those observed by Reider et al. (2013). The models that included interspecific interactions with larger taxa (e.g., trample, predators, or human models) did not receive substantial support given the data for Oophaga and revealed almost no association with occupancy or detection. This corresponds with our biological expectation, because dart frogs are aposematic and toxic so we would expect fewer strong direct interactions between this species and their relatively few potential predators (mostly birds - Paluh et al. 2015) or tramplers 
because they are obvious to humans who can avoid stepping on them. However, there was a negative association between dart frog detection and temperature. This suggests that increasing temperature at the time of the surveys negatively affects our ability to detect frogs when present. This observation also makes biological sense since frogs likely take refuge in leaf litter during the heat of the day (Whitfield et al. 2014), which should be taken into consideration in repeated monitoring surveys. The occupancy results suggested a relationship between frog occurrence and forest age. There seemed to be a higher probability of Oophaga occurrence in secondary forest, both in core La Selva and outside in other fragmented forest patches. This result corresponds with previous research that suggests strawberry poison dart frogs are resilient and relatively common in secondary growth forests (Mckone et al. 2014).

Contrary to the poison dart frog occupancy models confirming our hypotheses, the occupancy models for leaf litter frogs did not correspond with our a priori predictions. The most supported model showed higher estimated occurrence probabilities in forest fragments as compared to core La Selva. The negative association between leaf litter frog occurrence and core forest could be a signal of strong predator interactions because predators were significantly more abundant in core La Selva compared to forest fragments (Fernandez and Cove 2016), but this requires further investigation and species-specific diet analyses. Unfortunately, the predator models failed to converge and resulted in nonsensical estimates of predator effects, suggesting that the models were overfit to the data or there was difficulty estimating a parameter effect close to either boundary (e.g., 0 or 1). Similarly, Paluh et al. (2015) observed that brown frog models (e.g, representative of Craugastor or Pristimantis) were more commonly consumed than poison dart frog models, signaling more support for predation pressure as a potential mechanism underlying reduced leaf litter frog occupancy in core La Selva. Furthermore, the human model received model support and suggested a negative correlation between human detections at a site and leaf litter frog occurrence. These species proved to be very difficult to observe, which could lead to higher rates of trampling by researchers, as well as larger mammals, which likely affects their site occupancy. The influence of heavy human foot traffic, particularly of researchers and students in tropical research stations, might warrant further investigation because humans could influence leaf litter dynamics via trampling, but also potentially inadvertently introduce toxins such as insect repellent or sunscreen into the environment (e.g., DEET - Costanzo et al. 2007). The presence of human trails can confound inferences about leaf litter frog populations because we observed that this species group is more detectable on human trails, which is most likely a consequence of reduced leaf litter for refuge or cover. Additionally, if frogs were more detectable by surveyors then they are likely more detectable by predators along human trails due to limited leaf litter cover and this warrants further research to examine synergistic effects of human trail presence, humans trampling leaves, and predator abundance along these trails.

The model results for the experimental surveys with plastic Oophaga frog models showed no correlation between detection probability and the covariates that we 
examined. This was the expected result because the experiment was set up with completely random distribution of plastic frog models. Strawberry poison dart frogs, despite their aposematic coloring, were still not detected with $100 \%$ certainty when they were known to occur at a site and detection probabilities were lower than $90 \%$. The plastic leaf litter frog experimental survey results suggested that survey time was a factor in detection of the cryptic plastic frog models. These plastic frog models were much more difficult to detect and the more time spent searching the site for the frogs corresponded with decreased detection probability with a mean $\sim 70 \%$. However, this trend in detection decreasing with increasing survey time is likely an artifact of sampling areas with a substantial amount of leaves, stems, debris and downed trees that make it more difficult to survey and took longer but those obstacles also made it more difficult to detect leaf litter frogs.

Our observational and experimental studies revealed that Neotropical leaf litter frog communities are difficult to detect when present and future surveys would benefit from explicitly accounting for detection bias to accurately monitor trends of these threatened ecological indicators (Mazerolle et al. 2007). For example, Reider et al. (2013) noted that leaf litter was significantly higher through most of the year in peccary exclosures due to reduced trampling. Species that were detected more often in the control sites were very cryptic (Craugastor megacephalus and Pristimantis cerasi$n u s$ ); whereas the two most commonly detected anurans were Oophaga pumilio and C. bransfordii, which are more easily detectable due to their coloration, were not observed at different frequencies between control or exclosure sites (Reider et al. 2013). Therefore, it is probable that the trampling, rooting, and excavated earth created by peccaries, other large mammals, and humans could cause a positive detection bias in favor of altered habitats due to minimal cover for frogs to take refuge. These biases have the potential to make it difficult to discern significant differences in species composition or richness across studies in the tropics. We highly recommend that future surveyors take these biases into account in order to avoid drawing false inferences that could be important for endangered or rare species management (Ruiz-Gutierrez and Zipkin 2011).

\section{Acknowledgements}

We would like to thank the Organization for Tropical Studies and the La Selva Biological Station staff for their continued logistical support. Special thanks to Carissa Ganong, Adriana Baltodano, Leticia Classen, all the REU mentors and the many REU participants who helped and supported us during this process. Thanks to the Organization for Tropical Studies (OTS) and to Selva Verde Lodge, particularly Carlos de la Rosa, Orlando Vargas, Bernal Matarrita, Danilo Brenes, Ivan Castillo, and Gerardo Alvarez for their continued support. Funding for this research was provided by the National Science Foundation, Louis Stokes Alliances for Minority Participation and the Jack Kent Cooke Foundation. Our manuscript was further improved by incorporating comments from three anonymous reviewers and the editors. 


\section{References}

Carey C (2000) Infectious disease and worldwide declines of amphibian populations, with comments on emerging diseases in coral reef organisms and in humans. Environmental Health Perspectives 108(Suppl): 143-150. https://doi.org/10.1289/ehp.00108s1143

Costanzo SD, Watkinson AJ, Murby EJ, Kolpin DW, Sandstrom MW (2007) Is there a risk associated with the insect repellent DEET (, N-diethyl-m-toluamide) commonly found in aquatic environments? The Science of the Total Environment 384(1-3): 214-220. https://doi.org/10.1016/j.scitotenv.2007.05.036

Cove MV, Spinola RM (2014) Pairing Noninvasive Surveys with Capture-Recapture Analysis to Estimate Demographic Parameters for Dendrobates auratus from an Altered Habitat in Costa Rica. Phyllomedusa: Journal of Herpetology 12(2): 107. https://doi. org/10.11606/issn.2316-9079.v12i2p107-115

Cove MV, Fernandez CM, Vera Alvarez MD, Bird S, Jones D, Fagan ME (2017) Toucans descend to the forest floor to consume the eggs of ground-nesting birds. Food Webs 10: 2-4. https://doi.org/10.1016/j.fooweb.2017.01.003

Fernandez CM, Cove MV (2016) Examining the coupled effects of fragmentation and predators on ground nesting bird nest predation in the Neotropics. Organization for Tropical Studies 2016 REU Program Course Book: 126-137.

Hines JE (2012) Presence 5.1 - software to estimate patch occupancy and related parameters: USGS-PWRC. http://www.mbr-pwrc.usgs.gov/software/presence.html

Lips KR, Reeve JD, Witters LR (2003) Ecological Traits Predicting Amphibian Population Declines in Central America. Conservation Biology 17(4): 1078-1088. https://doi. org/10.1046/j.1523-1739.2003.01623.x

Mackenzie DI, Nichols JJ, Royle J, Pollock K, Bailey L, Hines J (2006) Occupancy estimation and modeling: Inferring patterns and dynamics of species occurrence. Amsterdam, Elsevier, 344 pp.

Mazerolle MJ, Bailey LL, Kendall WL, Royle JA, Converse SJ, Nichols JD (2007) Making great leaps forward: Accounting for detectability in herpetological field studies. Journal of Herpetology 41(4): 672-689. https://doi.org/10.1670/07-061.1

Mckone MJ, Moore JW, Harbison CW, Holmen IC, Lyons HC, Nachbor KM, Wheeler GR (2014) Rapid collapse of a population of Dieffenbachia spp., plants used for tadpolerearing by a poison-dart frog (Oophaga pumilio) in a Costa Rican rain forest. Journal of Tropical Ecology 30(06): 615-619. https://doi.org/10.1017/S0266467414000467

Michel NL, Sherry TW, Carson WP (2014) The omnivorous collared peccary negates an insectivore-generated trophic cascade in Costa Rican wet tropical forest understorey. Journal of Tropical Ecology 30(01): 1-11. https://doi.org/10.1017/S0266467413000709

Paluh DJ, Kenison EK, Saporito RA (2015) Frog or fruit? The importance of color and shape to bird predators in clay model experiments. Copeia 103(1): 58-63. https://doi. org/10.1643/CE-13-126

Pardo LE, Cove MV, Spinola RM, Cruz JC, Saenz JC (2016) Assessing species traits and landscape relationships of the mammalian carnivore community in a neotropical bio- 
logical corridor. Biodiversity and Conservation 25(4): 739-752. https://doi.org/10.1007/ s10531-016-1089-7

Pardo LE, Lafleur L, Spínola RM, Saenz J, Cove MV (2017) Camera traps provide valuable data to assess the occurrence of the Great Curassow Crax rubra in northeastern Costa Rica. Neotropical Biodiversity 3(1): 182-188. https://doi.org/10.1080/23766808.2017.1 346548

Phillips K (1990) Where Have All the Frogs and Toads Gone? Bioscience 40(6): 422-424. https://doi.org/10.2307/1311385

Reider KE, Carson WP, Donnelly MA (2013) Effects of collared peccary (Pecari tajacu) exclusion on leaf litter amphibians and reptiles in a Neotropical wet forest, Costa Rica. Biological Conservation 163: 90-98. https://doi.org/10.1016/j.biocon.2012.12.015

Romero A, O’Neill BJ, Timm RM, Gerow KG, Mcclearn D (2013) Group dynamics, behavior, and current and historical abundance of peccaries in Costa Rica's Caribbean lowlands. Journal of Mammalogy 94(4): 771-791. https://doi.org/10.1644/12-MAMM-A-266.1

Ruiz-Gutierrez V, Zipkin EF (2011) Detection biases yield misleading patterns of species persistence and colonization in fragmented landscapes. Ecosphere 2(5): art61. https:// doi.org/10.1890/ES10-00207.1

Whitfield SM, Bell KE, Philippi T, Sasa M, Bolanos F, Chaves G, Donnelly MA (2007) Amphibian and reptile declines over 35 years at La Selva, Costa Rica. Proceedings of the National Academy of Sciences of the United States of America 104(20): 8352-8356. https:// doi.org/10.1073/pnas.0611256104

Whitfield SM, Reider K, Greenspan S, Donnelly MA (2014) Litter dynamics regulate population densities in a declining terrestrial herpetofauna. Copeia 2014(3): 454-461. https://doi.org/10.1643/CE-13-061 